\title{
A PEDAGOGIA E O SISTEMA PRISIONAL: A EDUCAÇÃO EM AMBIENTE NÃO ESCOLAR
}

\author{
PEDAGOGY AND THE PRISON SYSTEM: EDUCATION IN A NON-SCHOOL \\ ENVIRONMENT
}

\author{
Nívea Maria Pimentel Quaresma ${ }^{1}$ \\ Rafael dos Santos Rocha ${ }^{2}$ \\ Luzilene Alves Cruz ${ }^{3}$
}

\begin{abstract}
RESUMO: O presente artigo faz uma análise sobre A Pedagogia e o Sistema Prisional, assim, a pesquisa teve por objetivo verificar sua contribuição para o processo de ressocialização. Histórico da Educação Prisional no Brasil, Eca e Direito humanos: Educação Presidiária, Pedagogia social e a sua importância na ressocialização carcerária. Tendo como embasamento teórico Foucalt e Eliane Vasquez. Trata-se de uma pesquisa de natureza qualitativa cuja coleta de dados foi bibliográfica, documental. Assim, os resultados obtidos neste trabalho confirmam que a Pedagogia social auxilia na reinserção do indivíduo a sociedade. É uma forma de promover o direito a educação a todos, independentemente de onde o indivíduo se encontra. Numa perspectiva interdisciplinar, além de ajudar na construção da identidade social do apenado.
\end{abstract}

Palavras-chave: Educação Penitenciaria; Pedagogia e o Sistema Prisional; Pedagogia Social.

ABSTRACT: This paper analyzes Pedagogy and the Prison System. Thus, the research aimed to verify its contribution to the resocialization process. History of Prison Education in Brazil, Human Eca and Law: Presidential Education, Social Pedagogy and its importance in prison resocialization. Having as theoretical basis Foucalt and Eliane Vasquez. This is a qualitative research whose data collection was bibliographic, documentary. Thus, the results obtained in this work confirm that social pedagogy helps in the reintegration of the individual into society. It is a way of promoting the right to education for all, regardless of where the individual is. In an interdisciplinary perspective, besides helping in the construction of the social identity of the inmate.

Keywords: Penitentiary Education; Pedagogy and the Prison System; Social pedagogy.

INTRODUÇÃO

\footnotetext{
${ }^{1}$ Graduação em Pedagogia pela Universidade Federal do Amapá- UNIFAP (2019). Professora de Ensino Infantil Municipal Recrutinha/Oiapoque-AP.E-mail:nivea.unifap.ped2or6@gmail.com.

${ }^{2}$ Graduação em Pedagogia pela Universidade Federal do Amapá- UNIFAP (2019). Professor de Ensino Infantil Municipal Recrutinha/Oiapoque-AP.E-mail:diflenrafael@gmail.com.

3 Graduação em Pedagogia pela UFBA e especialista em Educação Infantil e anos iniciais pela UnP. Docente do Colegiado do Curso de Pedagogia da Universidade Federal do Amapá. Atualmente responde pela Departamento de Educação a Distância da UNIFAP.E-mail:luzilene.cruz@unifap.br.
} 
A pesquisa intitulada "A pedagogia e o sistema prisional: A educação em ambiente não escolar", de acordo com os procedimentos, caracteriza-se como pesquisa bibliográfica que consiste em reunir os dados nos quais a investigação será baseada através da leitura, análise e interpretação do material selecionado, com realização de anotação e fichamentos.

No que diz respeito a sua finalidade caracteriza-se como uma pesquisa básica, teórica e descritiva, orientada para um aprofundamento de um conhecimento científico que já foi estudado.

A pesquisa surgiu ao participarmos de uma aula na casa de custódia do município de Oiapoque. E ao analisarmos as condições do ambiente carcerário, gerou curiosidade em pesquisar sobre este tema e como a educação em cárceres poderia intervir, para uma melhoria para os detentos e para sociedade que irão recebê-lo.

Após esta aula de campo fomos pesquisar a respeito deste assunto e descobrimos que originalmente as prisões foram criadas como alternativas mais humanas aos castigos corporais e à pena de morte. Em segundo momento, estas deveriam atender as necessidades sociais de punição e proteção enquanto promovessem a reeducação dos infratores.

Tal aquisição é de grande valia para sociedade, pois visto que, a reeducação carcerária contribui para diminuição da prática de novos delitos, oferecendo condições a uma educação de qualidade para os reeducando e favorecendo uma nova oportunidade de iniciar sua vida pós-cárcere.

Cada um tem sua parcela de responsabilidade nessa meta social das mais dignas para todo o povo brasileiro. A Educação como um segmento da sociedade, deve assumir efetivamente seu papel.

\section{HISTÓRICO DA EDUCAÇÃO PRISIONAL NO BRASIL}

Historicamente a educação prisional perpassa uma série de movimentos e modificações até o que é hoje na atualidade. Para abordar a respeito de educação em cárceres, é antes de qualquer coisa, é imprescindível referir o histórico do sistema prisional e suas penas, para que assim venha ser transcrevido a respeito de educação em cárceres, ambas estão coesas, pois ao longo da pesquisa será visto que somente a partir de estudos e alterações do sistema prisional que surge às primeiras reflexões e mobilização para uma educação em presídios para reabilitação e ressocialização de apenados.

O crescimento vertiginoso da massa apenada e do déficit de vagas, a respeito dos esforços governamentais e estados da federação para a geração de novas vagas, é no que lhe concerne um 
elemento revelador de que a edificação de novas unidades não podem mais ser o componente fundamental das políticas penitenciárias, senão que apenas mais um elemento, dentro de um mosaico bem mais amplo.

É bem verdade que dentre a superlotação de estabelecimentos penitenciários e a qualidade desses serviços subsiste uma relação de mútua implicação. Mas ainda assim, restam outros fatores que devem ser trabalhados junto à gestão dos sistemas penitenciários estaduais, como tática para torná-los melhores.

O nível educacional geralmente baixo das pessoas que entram no sistema carcerário reduz seus atrativos para o mercado de trabalho. Isso sugere que programas educacionais pode ser um caminho formidável para preparar os detentos para um retorno bem-sucedido à sociedade.

No século XVIII ainda não era falado em uma educação em cárcere para reabilitação para o penitenciado, apenas suplícios e castigos sádicos, como perspectiva de uma possível solução do delito cometido. Segundo Foucault (2013, p.17):

[...] no começo do século XVIII, o autor de Hanging, e que teria permitido arrebentar um condenado sobre a roda, depois açoitá-lo até a perda dos sentidos, em seguida suspendê-lo com correntes, antes de deixá-lo morrer lentamente de fome. Não mais aqueles suplícios em que o condenado era arrastado sobre uma grade (para evitar que a cabeça arrebentasse contra o pavimento), seu ventre aberto, as entranhas arrancadas às pressas, para que ele tivesse tempo de as ver com seus próprios olhos ser lançadas ao fogo; em que era decapitado enfim e seu corpo dividido em postas.

Neste período, citado pelo Foucault, ainda se tinha uma ideia de uma pena voltada totalmente para o castigo corporal, com suplícios próprios do ato de punir para consequência pelo delito praticado. Onde o pensamento de reabilitação do apenado não era relevante neste momento.

O período em que parcialmente o suplício foi esvanecendo-se como principal meio de punição foi nos períodos de I830 a I848 (Foucault, 2013, p. 17). É valido dizer que esse processo não ocorreu em único período em termo global, mas que a partir desses primeiros movimentos ocorridos nos Estados Unidos e Europa trouxe influencia para outros países como o Brasil (VALQUEZ, 2015, p.3I).

No Brasil, somente nos meados dos anos 5o, constatou-se o insucesso deste sistema prisional, o que motivou a busca de novas orientações, originando a inserção da educação escolar nas prisões. Foucault (1987, p. 224) diz: "A educação do detento é, por parte do poder público, ao mesmo tempo, uma precaução indispensável no interesse da sociedade e uma obrigação para com o detento, 
ela é a grande força de pensar".

A grande maioria dos indivíduos aprisionados não tiveram melhores possibilidades ao longo de suas vidas, sobretudo a oportunidade de estudar para garantir um futuro melhor. Nesse sentido, o tempo que gastará atrás das grades pode e deve ser utilizado para lhe garantir estas oportunidades que não houve, através de estudo e, paralelamente, de trabalho profissionalizante. Além de ajeitar as celas, lavar corredores, limpar banheiros, etc., os detentos precisam ter a chance de demonstrarem valores que, na maioria das vezes, encontram-se ofuscados pelo estigma do crime.

Existem casos de detentos que demonstram dotes artísticos, muitos deles se revelando excelentes pintores de quadros e painéis de parede, além de habilidades com esculturas, montagens, modelagens, marcenaria, etc. Também, decoram as celas de acordo com sua criatividade e sua personalidade. Estas artes devem ser incentivadas, pois, é uma forma de ocupar o preso, aumentando sua autoestima. É a chance de mostrar a ele de que existe a esperança de um amanhã melhor além das grades que o separam do mundo exterior.

As superlotações, os envolvimentos de presos em organizações criminosas e a falta de pessoal, são os principais problemas enfrentados pelas penitenciárias brasileiras. Outro fator que estamos habituados a ver nos noticiários é a questão das rebeliões em presídios, sempre com resultados lastimáveis de sentenciados que são mortos por seus próprios companheiros, funcionários e familiares de detentos transformados em reféns, resgates e fugas audaciosas e espetaculares realizadas por criminosos, e por fim, a incapacidade das autoridades em face de organizações de criminosos, cada vez mais presente nos Estados brasileiros.

Assistência ao Preso, ao Internado, ao Egresso e aos seus dependentes referir-se a um movimento de promover os direitos dos apenados, internados, egressos, dependentes e familiares, criando condições para que estes possam exercer a sua autonomia.

Esse processo deve ser mediado pela inclusão dos beneficiários na agenda das políticas públicas de governo e pelo apoio a ações de instituições públicas e privadas, de caráter permanente, que tenham como objetivo prestar atendimento aos beneficiários, na forma e nos limites da lei: material, jurídica, educacional, social, religiosa e principalmente à saúde ao egresso, após a edição do Plano Nacional de Saúde no Sistema Penitenciário.

É valido abordar também, sobre o surgimento do presídio no estado do Amapá que deu início no ano de 1944, que outrora a Fortaleza de São José era a cadeia pública, neste período. E que a 
construção penitenciaria se faz necessário.

Com isso, surgiu a Colônia Penal do Território do Amapá no governo do Capitão Jarary Gentil Nunes e a implantação de educação no sistema prisional surge em meados do século XX, com incentivo do ministério da educação em erradicação do analfabetismo no Brasil (Educação Pública, 2017, p 20).

\section{ECA E DIREITOS HUMANOS: EDUCAÇÃO PRESIDIÁRIA}

Para que se desenvolvam, neste presente artigo, reflexões concernentes ao universo de aspectos relativos a toda matéria criminal posta na lei 8.069 - o Estatuto da Criança e do Adolescente - imperiosa é a conceituação daquilo que aquela Lei batiza como Ato Infracional.

\subsection{Ato Infracional - parte penal do ECA}

Artigo ro3 ECA. Considera-se ato infracional a conduta que, praticada por criança ou adolescente, é definida em lei como crime ou 4 contravenção penal.

Se um adulto pratica é crime de roubo, se um adolescente pratica é ato infracional, sanção, medida socioeducativa. $O$ que para o adulto é infração penal para o adolescente é ato infracional. O ECA vai pegar do CP a definição dessas condutas, somente vai trocar a consequência, que no CP é pena e no ECA é medida socioeducativa.

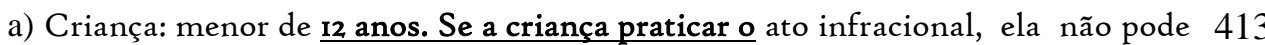
receber medida socioeducativa, ela somente pode receber as chamadas medidas de proteção que não tem caráter de sanção e, entre elas não esta a FEBEM, pois internação é medida socioeducativa e criança somente pode receber as medidas de proteção previstas no artigo Ior do ECA que são: encaminhamento aos pais ou responsável; matricula obrigatória em ensino fundamental. Para criança, nunca pode ser aplicada medida socioeducativa. A criança é encaminhada ao Conselho Tutelar, para que ele aplique as medidas de proteção.

b) Adolescente: $O$ adolescente é encaminhado para a autoridade judicial ou adolescente também pode receber as medidas de proteção. Assim, o adolescente pode receber medidas quaisquer. Somente pode receber as socioeducativas, adolescentes que tenham praticado ato infracional.

A idade que importa é a do momento em que ocorreu o fato, a idade no dia da ação ou omissão - Teoria da atividade.

A conduta da criança ou do adolescente, quando revestida de ilicitude, repercute obrigatoriamente no contexto social em que vive. E, a despeito de sua maior incidência atualmente, sobretudo nos países subdesenvolvidos ou em desenvolvimento, tal fato não constitui ocorrência apenas deste século, mas é nesta quadra da história da Humanidade que o mesmo assume proporções

\footnotetext{
${ }^{4}$ Grifo dos autores.
} 
alarmantes, principalmente nos grandes centros urbanos, não só pelas dificuldades de sobrevivência como, também, pela ausência do Estado nas áreas da educação, da saúde, da habitação e, enfim, da assistência social.

Por outra parte, a falta de uma política séria em termos de ocupação racional dos espaços geográficos, a ensejar migração desordenada, produtora de favelas periféricas nas capitais dos Estados, ou até mesmo nas médias cidades, está permitindo e vai permitir, mais ainda, pela precariedade de vida de seus habitantes, o aumento, também, da delinquência infanto-juvenil.

A sua erradicação, ou, ao menos, a sua gradativa diminuição, depende mais da atuação correta da Administração Pública, nos três níveis de governo, do que daqueles que se encontram nessa faixa etária. É verdade que a orientação nascida no próprio berço configura, sem sombra de dúvida, o melhor caminho para determinar o comportamento da criança e do jovem.

Mas, sem lar, ou com pais ausentes, ao largo dos dias que fluem, sem o atendimento das mínimas necessidades, as portas se abrem às mais negras perspectivas. E, a partir daí a prática de infrações penais, que deveria constituir-se "num fato excepcional", a colocar no mesmo nível dos criminosos adultos os menores que convivem habitualmente no mundo da criminalidade. Daí, segundo Wilson Barreira e Paulo Roberto Grava Brazil, a necessidade de investir-se "na área preventiva, de modo a que os menores infratores habituais, estes que fazem da infração meio de 414 sobrevivência, não mais necessitem praticá-las” (O Direito do Menor na Nova Constituição, São Paulo, Atlas, 1989, p. 25).

Acentue-se ser esta a grande solução, que, apesar de complexa e onerosa, por envolver muito mais do que a pessoa da criança e do jovem, não pode ser postergada e nem sofrer, nas sucessões de governo, solução de continuidade.

Nem todos os fatos incluem-se na esfera de interesse do Direito. Ingressa nesta área, entre tantos outros, o comportamento humano visto sob a ótica de sua ilicitude. Com tal contorno, é o procedimento pessoal objeto de particular consideração no Direito Privado, no Direito Público e no Direito Social. Em qualquer dessas áreas, o fato contraveniente da norma que redunde em malefício aos interesses patrimoniais ou aos direitos da personalidade acarreta para o lesado o direito à indenização ou à reparação do dano, com a ressalva de que nem todo ilícito civil configura ilícito de natureza penal.

Se o dano repercutir apenas na esfera do direito privado, por ele responde o agente segundo 
as regras próprias da responsabilidade civil. Tratando-se de menor de 16 anos, vigora o preceito segundo o qual os pais passarão a ser responsáveis pela reparação desde que, por ocasião do respectivo prejuízo, estivesse aquele sob o pátrio poder em sua companhia (art. I.52I, I, do CC).

Já, o menor entre I6 e 2i anos equipara-se ao maior quanto às obrigações resultantes de atos ilícitos em que for culpado, ex vi do art. 156 desse mesmo diploma. Ali, há responsabilidade exclusiva do pai, enquanto, nesta última hipótese, pode ter ensejo a solidariedade, segundo preleciona Maria Helena Diniz: “A responsabilidade dos pais será isolada se o filho tiver menos de 16 anos e solidária se tiver mais do que essa idade" (Curso de Direito Civil Brasileiro - Responsabilidade Civil7º/342, São Paulo, Saraiva, 1984).

A incidência de tais dispositivos poderá ter origem na violação de norma criminal ou contravencional. O seu agente responderá segundo as regras do Direito repressivo e, se for o caso, também do Direito Civil, pelo fato cuja ilicitude seja objeto de consideração, em simultâneo, desses dois ramos da Ciência Jurídica. Mas, se for menor de 18 anos, a punibilidade cede passo à aplicação de medidas sócio-educativas e o dano deverá ser apurado, para efeito de imputação e responsabilização, segundo a disciplina própria do Código Civil e do próprio Estatuto da Criança e do Adolescente (art. i16).

Em outras palavras, impende acentuar que o ilícito puramente civil pode ensejar o direito à recomposição do correspondente prejuízo. O ilícito penal, apesar de adentrar a esfera da responsabilidade civil, gera sempre uma penalidade em relação às pessoas imputáveis, que não se estende, entretanto, aos menores de i8 anos, por considerações que serão elencadas ao ser analisado o art. 104 do referido Estatuto.

A delinquência, no seu sentido amplo, que tenha como protagonista a criança ou o adolescente vem alargando seus limites, sem a possibilidade de um pronto estancamento, e tem merecido tratamento diferenciado em relação às infrações praticadas por agentes capazes e imputáveis. Daí porque o estabelecimento, pelo legislador, de critérios e princípios acerca dos atos infracionais e bem assim sobre as medidas a serem aplicadas aos menores de 18 anos.

O título III da Parte Especial- "Da prática do ato infracional” - abrange pontos de natureza substantiva e, em simultâneo, adjetiva. Assim, a par do conceito de ato infracional, dos direitos e garantias individuais e processuais, cuida, também, das medidas sócio-educativas e, finalmente, no último capítulo, da remissão, para exclusão ou, então, de suspensão ou extinção do processo. 
Posto isto, cumpre cingir-se, daqui a para frente, ao primeiro dos três artigos que compõem as disposições gerais do aludido título.

A infração penal, como gênero, no sistema jurídico nacional, das espécies crime ou delito e contravenção, só pode ser atribuída, para efeito da respectiva pena, às pessoas imputáveis, que são, em regra, no Brasil, os maiores de 18 anos. A estes, quando incidirem em determinado preceito criminal ou contravencional, tem cabimento a respectiva sanção. Abaixo daquela idade, a conduta descrita como crime ou contravenção constitui ato infracional. Significa dizer que o fato atribuído à criança ou ao adolescente, embora enquadrável como crime ou contravenção, só pela circunstância de sua idade, não constitui crime ou contravenção, mas, na linguagem do legislador, simples ato infracional.

O desajuste existe, mas, na acepção técnico-jurídica, a conduta do seu agente não configura uma ou outra daquelas modalidades de infração, por se tratar simplesmente de uma realidade diversa. Não se cuida de uma ficção, mas de uma entidade jurídica a encerrar a ideia de que também o tratamento a ser deferido ao seu agente é próprio e específico.

Assim, quando a ação ou omissão venha a ter o perfil de um daqueles ilícitos, atribuível, entretanto, à criança ou ao adolescente (v. art. $2^{\circ}$ ), são estes autores de ato infracional com consequências para a sociedade, igual ao crime e à contravenção, mas, mesmo assim, com contornos diversos, diante do aspecto da inimputabilidade e das medidas a lhes serem aplicadas, por não se assemelharem estas com as várias espécies de reprimendas.

Para o crime e para a contravenção comina-se pena no seu mais puro significado. Já, para os atos infracionais, em relação à criança tem cabimento seu encaminhamento aos pais ou responsáveis, mediante termo de responsabilidade; orientação, apoio e acompanhamento temporários; matrícula e frequência obrigatórias em estabelecimento oficial de auxílio à família, à criança e ao adolescente; requisição de tratamento médico, psicológico ou psiquiátrico, em regime hospitalar ou ambulatorial; inclusão em programa oficial ou comunitário de auxílio, orientação e tratamento a alcoólatras e toxicômanos; abrigo em entidade e colocação em família substituta (art. I05, c/c o art. IOI, do Estatuto). Os adolescentes sujeitam-se, entretanto, a advertência; obrigação de reparar o dano; prestação de serviços à comunidade; liberdade assistida; inserção em regime de semiliberdade; internação em estabelecimento educacional e qualquer uma das previstas no Art. IoI, I a VI (art.II2). 


\subsection{Medidas Socioeducativas - não privativas de liberdade.}

A medida socioeducativa se decompõe em diversas modalidades que são aplicadas de acordo com o grau da infração praticada, cada uma com sua razão de ser. O Estatuto da Criança e do Adolescente prevê desde a advertência até a privação de liberdade ao menor infrator. Assim trata em seu artigo II2:

Artigo I12 ECA - praticadas somente para os adolescentes.

São chamadas de medidas em meio aberto, pois não priva a liberdade.

1. Advertência: artigo IIs ECA - consiste em uma admoestação oral que será reduzida a termo.

2. Reparação dos danos: sanção por ato infracional. Promova o ressarcimento dos dano, ou, por outra forma, compense o prejuízo causado à vítima. Artigo II6 ECA.

3. Prestação de serviços comunitários: artigo II7 do ECA. O juiz pode aplicar essa medida por no máximo 6 meses com jornada semanal de oito horas.

4. Liberdade assistida: ainda não foi privado da liberdade, apenas terá assistência. $O$ juiz designa para ela um orientador nomeado pelo juiz que vai acompanhar o adolescente na sua vida familiar, comunitária e escolar. O prazo é de no mínimo 6 meses.

Adolescentes portadores de doença ou deficiência mental receberão tratamento individual especializado, não serão submetidos a medidas socioeducativa.

\subsection{Cabimento taxativo da internação}

Artigo 122 ECA. Só se aplica à internação, pois às demais são livremente aplicáveis. É possível a internação quando se tratar de ato:

1. Cometido ou praticado com violência ou com grave ameaça à pessoa. Ex: atos equiparados a crimes de roubo, homicídio, estupro. Para ato equivalente a furto não é cabível internação como medida socioeducativa, podendo ser aplicada qualquer uma das outras cinco medidas. E se ele for pego praticando ato equivalente à tráfico de drogas? $\mathrm{O}$ tráfico de drogas para o adulto é crime equiparado ao hediondo, mas o requisito que o ECA elege para poder caber ou não a internação é se tem violência ou grave ameaça à pessoa e no caso do tráfico de drogas não existe essa violência. Juiz aplica sem prazo até o limite de 3 anos.

2. Configurada reiteração no cometimento de atos graves.

a palavra reiteração, que é fazer de novo, é pensada do segundo ato em diante. Assim, se praticar 3 atos ele pode ser internado. Trafico de drogas entra nesse caso, mas somente depois de 3 vezes, no mínimo 2. Juiz aplica sem prazo até o limite de 3 anos.

Descumprimento reiterado e injustificável de outra medida anteriormente 
aplicada: chamada de internação com prazo determinado ou internação sanção. Assim, uma vez aplicada a mediada por sentença em processo de conhecimento, cabe ao adolescente a ela submeter-se, independentemente de sua vontade. Se assim não o fizer poderá sujeitar-se à internação sanção, cujo prazo de duração poderá chegar a 3 meses. A reiteração pressupõe mais de 3 atos. Poderá internar em razão do descumprimento reiterado e injustificável de outra medida anteriormente aplicada. Se vai internar porque ele esta descumprindo outra medida é porque a outra medida não era a internação. A ideia é que na sentença o juiz aplicou uma medida mais branca, mas o sujeito vem descumprindo a medida retiradamente, desse modo, o juiz decidira pela internação breve de modo a fazer com que o sujeito seja obrigado a cumprir a medida e conscientiza-lo, convence-lo de que ele deve cumprir a medida anterior. Ira internar por no máximo 3 meses e depois o sujeito volta a cumprir a medida anteriormente aplicada. Antes do juiz aplicar a sanção ele deve ouvir o adolescente, pois se isso é sanção por descumprir outra, não pode aplicar nova sanção sem o contraditório e ampla defesa. Assim, deve-se ouvir o adolescente em audiência para que ele possa justificar o porque descumpriu a medida. Antes de aplicar a internação sanção o juiz deve ouvir o adolescente permitindo assim que ele possa justificar o descumprimento alegado, pois se esse descumprindo foi justificado, não se aplica sanção.4. Internação provisória: é aquela internação aplicada antes da sentença e é provisória, pois antecede a decisão definitiva. O limite é o de 45 dias, se nesse período não sobrevier sentença o juiz terá de soltar o adolescente. Esse prazo é improrrogável. Se der o prazo tem que soltar o adolescente para que ele aguarde em liberdade a sentença que lhe condenará.

Por fim, faz-se relevante mencionar que, dada a finalidade pedagógica da medida institucional de internação, embora contando com uma natureza aflitiva, não poderá haver casos de incomunicabilidade do adolescente no cumprimento da medida socioeducativa, e a proibição de visitas só poderá ocorrer se existirem motivos sérios e fundados da prejudicialidade da presença de pais ou responsáveis aos interesses dos adolescentes.

\section{PEDAGOGIA SOCIAL E A SUA IMPORTÂNCIA NA RESSOCIALIZAÇÃO CARCERÁRIA.}

A violência no Brasil vem crescendo e por consequência tem criado muita discussão quanto às providências e medidas que devem ser tomadas para enfrentar e melhorar o sentimento de segurança por parte da sociedade. Muitos são os intendimentos sobre o assunto, mas prepondera à opinião sobre repressão no combate ao crime, recrudescimento de penas e construção de presídios de segurança máxima.

A sociedade afligida pelo medo protesta pelo afastamento dos autores da violência do convívio social. Entretanto o que acontece é que as pessoas desejam o encarceramento desses indivíduos, mas esquecem que depois do cumprimento da pena por esse indivíduo, ele estará de volta 
à sociedade.

Percebe-se que, não há nenhuma preocupação pela maior parte dos cidadãos com a ressocialização dos presos, motivo pelo qual esta pesquisa demonstra a possibilidade de mudança de comportamento daquele ser humano que se encontra vulnerável quando fica privado de sua liberdade e no momento de retorno à sociedade, construindo alguns projetos de políticas públicas, em específico na área da educação, os quais buscam formas de reduzir a taxa de reincidência e consequentemente à prevenção da criminalidade dentro e fora do cárcere.

Por essa ótica analisamos o porquê e o que ensinar nos presídios, e visto que, de acordo com a Lei de Execução Penal:

Da Assistência Educacional.

Art. 17. A assistência educacional compreenderá a instrução escolar e a formação profissional do preso e do internado.

Art. I8. O ensino de Io grau será obrigatório, integrando-se no sistema escolar da Unidade Federativa.

Art. 19. O ensino profissional será ministrado ao nível de iniciação ou de aperfeiçoamento técnico.

Parágrafo único. A mulher condenada terá ensino profissional adequado à sua condição.

Art. 20. As atividades educacionais podem ser objeto de convênio com entidades públicas ou particulares, que instalem escolas ou ofereçam cursos especializados.

Art. 21. Em atendimento às condições locais, dotar-se-á cada estabelecimento de uma 419 biblioteca, para uso de todas as categorias de reclusos, provida de livros instrutivos, recreativos e didáticos.

A educação é considerada como um dos meios de promover a integração social e a aquisição de conhecimentos que permitam aos reclusos assegurar um futuro melhor quando recuperar a liberdade. Essa posição talvez seja compartilhada pelos apenados que compreendem que o encarceramento tem uma finalidade que vai além do castigo, da segregação e da dissuasão e que, portanto, aceitam voluntariamente e aprovam o aspecto reformador do encarceramento, em especial as atividades de educação profissional e as informações sobre oportunidades de emprego.

Outros apenados, ao contrário, rechaçam a educação como parte de um sistema impositivo e castrador, que os querem alienados. Sem dúvida alguma, por outro lado, é possível ainda que muitos apenados participem inicialmente das atividades educativas por razões alheias à educação; por exemplo: sair das suas celas, estarem com amigos ou evitar o trabalho, etc.

Levando-se em consideração que o cárcere tem como objetivo central a reinserção social do apenado, deverá estar estruturado de forma que possibilite, a qualquer custo, garantir os direitos fundamentais do interno (integridade física, psicológica e moral), viabilizando a sua permanência 
dignamente e capacitando-o para o convívio social e para o seu desenvolvimento pessoal e social.

Compreendendo a educação como o único processo capaz de transformar o potencial das pessoas em competências, capacidade e habilidades - o mais (saúde, alimentação, integridade física, psicológica e moral) é condição para a efetivação da ação educativa - e educar como o ato de criar espaços para que o educando, situado organicamente no mundo, empreenda a construção do seu ser em termos individuais e sociais, o espaço carcerário (de privação de liberdade), com todas as suas idiossincrasias, deve ser entendido como um espaço educativo, ambiente socioeducativo.

Assim sendo, todos que atuam nessas unidades (pessoal dirigente, técnico e operacional) são educadores (socioeducadores) e devem, independente da sua função, estar orientados nessa condição. Todos os recursos e esforços devem convergir, com objetividade e celeridade, para o trabalho educativo. Ou seja, todas as unidades devem possuir um Projeto Político-Institucional que oriente as ações, defina os recursos e viabilize uma atuação consciente e consistente com o plano individual de trabalho do interno.

As ações educativas devem exercer uma influência edificante na vida do interno, criando condições para que molde sua identidade, buscando, principalmente, compreender-se e aceitar-se como indivíduo social; e construir seu projeto de vida, definindo e trilhando caminhos para a sua

vida em sociedade. Assim como devem existir educação escolar e a educação profissional no espaço carcerário como política de execução penal, hoje, também defendemos que deve existir uma proposta político-pedagógica orientada na socioeducação, cujo objetivo seja preparar o apenado para o convívio social.

\section{CONSIDERAÇÕES}

Não restam dúvidas que o papel da educação no cárcere deve ser de reeducar os criminosos e auxiliá-los a ter uma visão mais ampla de mundo, a buscar outras formas de inserção na sociedade, pois observamos que os detentos que tem acesso à escola estão mais acessíveis ao mercado de trabalho. É através do ensino que os encarcerados têm a oportunidade de se humanizarem e se transformar. A Educação é transformadora quando se quer transformar. $O$ ensino aprendizagem se faz com o professor por que ele é mediador.

O ambiente prisional vai muito além do espaço físico, "sala de aula", pois este espaço educativo nem sempre é suficientemente valorizado. Pode eventualmente o ambiente prisional favorecer aprendizagens corrosivas à índole do indivíduo, como: a repressão, ameaças, maus tratos, 
brigas, furtos, drogas, etc.

A sociedade dos encarcerados não é só fisicamente comprimida, mas também psicologicamente, visto que eles vivem em uma intimidade forçada, na qual o comportamento de cada homem está sujeito tanto à inspeção constante dos colegas cativos quanto à vigilância dos administradores.

A prisão subjuga o detento ao comando de uma estrutura autoritária de uma rígida rotina. Os presos não podem andar com os braços soltos ao lado do corpo, são obrigados a andar de braços cruzados e quando cruzarem por qualquer pessoa nos corredores da galeria, devem parar, virar de frente para a parede e esperar a pessoa passar e só depois seguir para onde estava se direcionando.

O aprisionado sofre uma deterioração de sua identidade, e lhe é forjada uma nova. Isso implica na desadaptação dos padrões convencionais e adaptação aos novos impostos pela instituição. Não existe um código, e sim a cautela, que é imprescindível ao convívio. Em suas ações cotidianas, ele sabe a quem deve obedecer; vê, ouve e tem conhecimento do que acontece, mas tem consciência de que às vezes é melhor não expressar verbalmente seu pensar.

Vale lembrar que a máscara e a duplicidade são meios de proteção contra todas as formas absolutizáveis. A máscara oferece um refúgio bastante seguro: permite o existir e propicia, fazendo como todo o mundo faz, o esconder-se.

A educação pode e deve contribuir para a formação de jovens e adultos, homens e mulheres justos e competentes, cidadãos autônomos e capazes de agir em sociedade de forma positiva. Deve preocupar-se com indivíduos preparando-os a assumir seu papel no trabalho e na sociedade. Quando se fala em ensino, se fala em relações de sujeito para sujeito, de sujeito com a vida, de formação básica e de formação tecnológica.

A educação é um direito fundamental de todos, homens e mulheres, de todas as raças, de todas as idades, no mundo todo; cada ser humano, criança, jovem ou adulto, deve ter condições de aproveitar as oportunidades educativas voltadas para satisfazer suas necessidades básicas de aprendizagem, independentemente do meio em que se encontram.

Nesse sentido, no cenário atual existem iniciativas e projetos que visam garantir esse direito aos presos. Com efeito, educação para todos não significa qualidade. Um ensino "burocrático”, conteudista que poderá oferecer uma boa base de conhecimentos, mas não levará a redução da criminalidade, talvez até ajude a sofisticá-los. 
O problema é complexo, não se pode dizer que investindo em educação nos presídios necessariamente vai diminuir a violência nas ruas. Mas a instrução prisional pode contribuir para as pessoas se desenvolverem e buscarem alternativas para a sua reinserção na sociedade.

Como ensinar? O que ensinar aos que estão atrás das grades? Quem ensina quem?

O educador deve ter sensibilidade e crer no ser humano e em sua capacidade de regeneração, compreendendo-o como um ser inacabado, com potencialidade e vivência a serem consideradas. Conhecer um pouco do seu cotidiano, seus sonhos, seus engajamentos culturais, sociais e políticos, nos aproximam cada vez mais deles e nosso olhar antes restrito vão se transformando em um novo olhar, mais rico e interessante, pois o papel do educador prisional é o de olhar a pessoa marcada por suas ações impensadas, com um olhar respeitoso, um olhar diferenciado.

Somente quando o preso sente a amizade sincera do educador, destas que não exige retorno, é que se inicia o processo de autoconfiança, é aqui que se dá à dialógica, revitalizando os seus próprios valores.

Os educadores deverão estar atentos às falhas dos presos e procurar interferir e orientá-los sempre que necessário, mostrando a importância das mudanças de comportamento para conquistar, lutar e ter direito a dignidade. Além das competências previstas em nossa proposta pedagógica devemos enfatizar valores, respeito, limites, responsabilidade, reflexão, auto-avaliação, capacidade de mudança, permitindo assim que o educando acredite e insista na possibilidade de mudança e persistência em seus objetivos, buscando assim a reestruturação social.

É de suma importância salientar que os educadores prisionais devem ser qualificados, com uma formação específica, especializada, para melhor atuar e conviver com os apenados, pois não podemos esquecer que são seres humanos fragilizados, marginalizados e que estão entre as grades por uma questão de exclusão da sociedade.

Uma das práxis pedagógicas mais satisfatórias nos presídios é lidar com os presos com amor, com delicadeza, agindo com naturalidade, mas com sinceridade, elogiando-os quando for oportuno, procurando dialogar sempre que sentirem a necessidade e estimulá-los com palavras otimistas de modo que possam sentir-se valorizados.

Nesse sentido acreditamos que o conhecimento é trazido pelo afetivo, o preso aprende bem o que lhe causa interesse, numa atmosfera de aula que lhe pareça segura, com um professor que sabe criar afinidades. A transmissão de conhecimento e, consequentemente, a aprendizagem acontece 
simultaneamente com a compreensão e valorização das pessoas envolvidas no processo educativo, pois deve haver um entrelaçamento entre educação e vida.

Há uma metodologia específica para que os docentes possam transmitir conhecimento a seus alunos encarcerados? Qual metodologia devemos aplicar? Em se tratando de um contexto diferenciado pode-se afirmar que não há uma metodologia específica ou um receituário, pois na prisão a cada dia surge uma nova realidade, diferenciada nas salas de aula; são presos que vão para o externo (trabalhar fora da prisão), outros estão chegando, outros doentes, mas cabe ao educador traçar suas práxis, e usar toda sua ternura, sensibilidade e criatividade para fisgar o preso e despertar seu interesse nas aulas.

Mas será que vale a pena investir em prisioneiros? Depois de tantos estudos chega-se a conclusão que sim, pois é nesse espaço que o professor pode colocar suas intenções de transformação, de mudar atitudes, capacidades e ideias. A escola é um meio de oportunizar a socialização, enquanto oferece ao aluno outras possibilidades referenciais de construção de sua identidade e de resgate da cidadania perdida.

Pode-se acreditar na ressocialização dos presidiários, caso contrário o trabalho dos educadores junto a eles não terão nenhuma valia. Vale a máxima que diz que o homem é do tamanho daquilo que pensa. Querendo ou não o educador se torna responsáveis por aqueles que educam. Se profissionais da educação prisional, com acesso direto com os presos não fizeram "a diferença", quem fará? A lei e a justiça são lentas, e devem permanecer assim, pois os criminosos são presos para que a sociedade possa livrar-se deles.

Sabe-se que, na prática não existe a reeducação do egresso como se almeja, porque a principal preocupação do sistema penitenciário ao receber um indivíduo condenado não é a sua reeducação, mas sim a privação de sua liberdade.

Também é importante ressaltar que o preso aproveita, ou acaba aproveitando a oportunidade para se educar, já que não o fez lá fora. E que sempre vale a pena investir na recuperação do ser humano, mesmo que isso exija um trabalho árduo e persistente ao educador.

Concluímos que a privação da liberdade única exclusivamente não favorece a ressocialização. Mas a educação prisional favorece a reintegração do indivíduo na sociedade.

É preciso desenvolver programas educacionais no sistema penitenciário que visem alfabetizar e construir a cidadania dos presos. A conscientização deve ser uma das práxis para a 
transformação do mundo dos presos, pois através da ação-reflexão é que formaremos novos cidadãos. Cabe ao poder público e a sociedade em geral se preocuparem e se comprometerem com a educação.

Também é fundamental que não seja esquecida a necessidade de investir em propostas políticas que viabilizem o retorno do egresso à sociedade, visto que as atuais estão um tanto ultrapassadas.

\section{REFERENCIAS}

BRASIL. Lei nº 7.210, de II de julho de 1984. Institui da Lei de Execução Penal. 1984. Disponível em http://www.planalto.gov.br/ccivil/leis/L7210.htm. Acesso03/o9/2019 as 22:32

BRASIL. Lei n̊ 9.394, de 20 de dezembro de 1996. Estabelece as Diretrizes e Bases da Educação Nacional Brasília. 1996. Disponível em: http://www.planalto.gov.br/ccivil_09394.htm. Acesso: 4 out. 2019.

BRASIL. Ministério da Justiça. Avaliação do Atendimento à população egressa do sistema penitenciário do Estado de São Paulo. Brasília, 2007. Acesso: 4 out. 2019.

BRASIL. Ministério do Desenvolvimento Social e Combate à Fome. Política Nacional de Assistência Social. Brasília, 2004. Acesso 04/09/2019 as 05:20

COSTA, Karina. Estudo deve diminuir pena em presídios. Disponível em: http://aprendiz.uol.com.br/content/thogesticl.mmp. Acesso 04/o9/2019

COYLE, Andrew. Administração Penitenciária: Uma abordagem de Direitos Humanos: Manual para Servidores Penitenciários. Londres: International Centre for PrisonStudies, 2002, p. 186. Acesso Data: 4 out. 2019.

DICIONÁRIO AURÉLIO. Disponível em: http://www.dicionariodoaurelio.com. Acesso o4 out. 2019.

EDUCAÇÃO, Secretaria Estadual de; PÚBLICA, Secretaria Estadual de JustiÇa e SeguranÇa. Plano estadual de educação para o sistema penitenciário amapaense. 2017. Disponíve<http://depen.gov.br/DEPEN/dirpp/cgpc/acocacao/planoestadualdasprisoesfinalzoo7amap.pdf $>$. Acesso em: 30 out. 2019.

FOUCALT, Michel. Vigiar e punir - História da violência nas prisões - Tradução de Raquel Ramalhete. 36. Ed. Petrópolis: Vozes, 2007. 
FREIRE, Paulo. Política e educação. São Paulo: Cortez, 1995.

MIRABETE, JulioFabrini; FABRINI, Renato. Execução Penal: Comentários à Lei n 7.210 , de II-71984. II. ed. São Paulo: Atlas, 2007, p. 874.

SAVIANI, Dermeval. Pedagogia histórico-crítica. ro. ed. São Paulo: Autores

SIMÕES, José Luis. Educação para as elites, escolas para os vadios e violência para todos. Revista Diálogos, São Paulo. v. 5, p. 93-10o, 2006.

SILVA, R.; MOREIRA, F. A. Apresentação. In: VASQUEZ, E. L,; FEIO, L. S. R.; ABREU, A. A. (Org's.). Anais do I Seminário de Políticas Públicas para Educação Penitenciária no Estado do Amapá. Rio de Janeiro: CBJE, 2013, p. 7.

TEIXEIRA, Carlos. Relato de experiência na educação carcerária. Revista Educação. São Paulo: segmento.

em:http://www.revistaeducação.uol.com.br/textos.asp?codigo=12037>. Acesso or/1o/2019

VÀZQUEZ, Adolfo S. Ética. Rio de Janeiro: Civilização Brasileira, 2003. 